\title{
O PROBLEMA DO INFIXO EM PORTUGUÊS
}

Valter Kehdi*

RESUMO: Neste artigo, faz-se o levantamento das diferentes propostas de existência de infixos em português, acompanhadas dos comentários críticos correspondentes. O objetivo é mostrar que provavelmente não existe, em nossa língua, esse tipo de morfema.

Palavras-chave: infixo, alternância vocálica, fonemas de ligação.

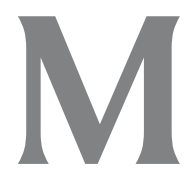

uitas gramáticas e dicionários especializados vêm se preocupando com a depreensão de infixos em português. Dada a diversidade dos casos apresentados, é oportuno que se faça um levantamento do que se escreveu sobre esse tema, o que nos possibilitará realizar uma análise crítica das diferentes propostas.

Cumpre, inicialmente, estabelecer o conceito de infixo em que nos baseamos, o que não é problemático, pois a maioria dos manuais e dicionários de Linguiística está de acordo em caracterizar o infixo como o morfema que se introduz no radical, diferentemente dos prefixos e sufixos. O exemplo mais frequiente é o do elemento nasal que figura no interior do radical de alguns verbos latinos e cuja função é caracterizar as formas do Infectum, em oposição às do Perfectum, desprovidas de nasal: uiNco/uici ${ }^{1}$. Em português, a extensão da nasal a todo o paradigma fez com que esta passasse a ser elemento integrante do radical: venço/venci. Dessa forma, a impossibilidade de transposição do exemplo latino para nossa língua acabou constituindo um estímulo para a investigação da existência de infixos em português.

Universidade de São Paulo.

1 Essa observação é válida do ponto de vista do latim clássico. Numa perspectiva indoeuropeística, a questão é bem mais complexa, relacionada ao fenômeno do "alargamento". Cf. Meillet \& Vendryes (1960, §238, p.156-7). 
Inicialmente, foram consideradas como infixos as consoantes de ligação: capin-z-al. Essa posição já se encontra em João Ribeiro (1906, s.v. infixo (p.180-1)); a Gramática portuguesa, de Mário Pereira de Souza Lima, bem posterior à obra de J. Ribeiro, com uma bibliografia notavelmente atualizada para a época de sua publicação, continua considerando o /z/ de ligação como infixo (1945, §261 (p.113)). Observandose, contudo, que, em capinzal, o /z/ se pospõe ao radical e não tem valor significativo, conclui-se que constitui, na realidade, um exemplo de consoante de ligação, como bem o notou Mattoso Câmara no Dicionário de fatos gramaticais (1956, s.v. infixo (p.124)). A influência de M. Câmara faz-se sentir na Nomenclatura Gramatical Brasileira, em cuja segunda parte - Morfologia, no item A. Estrutura das palavras, se reconhecem como afixos apenas os prefixos e os sufixos, apontando-se em seguida a existência de vogais e consoantes de ligação, posição mantida pelas gramáticas portuguesas posteriores à NGB.

Convém, todavia, reconhecer que, a rigor, os fonemas de ligação representam exemplos de "morfes vazios" em português, segundo a designação proposta por Hockett (1947, $§ 15$ (p.333)). Trata-se de elementos desprovidos de sentido, que não pertencem a nenhum morfema do vocábulo; com efeito, a ocorrência de capim e de -al, sem -z- (cf., para -al: bananal, laranjal, tomatal), leva-nos a depreender, em capinzal, o morfe vazio /z/. Posteriormente, propôs-se a integração desse elemento ao sufixo, que passava, assim, a apresentar-se sob a forma de variante: -all-zal.

Em seu artigo "Sobre a formação de palavras com prefixos em português actual”, Li Ching (1973, §16 (p.213)), ao elencar alguns pseudo-prefixos do português - aéro-, foto-, micro-, etc. (p. ex., em aeroclube, foto-câmara e microagulha), afirma:

"O terminus -o-, que é o eixo mais importante nesta série, é uma espécie do infixo da composição que se encontrou há muito tempo, sem dúvida nenhuma, nas formações adjectivas (cf. luso-brasileiro, luso-espanhol, etc.)".

Ora, considerando que o infixo só pode figurar no interior de radical, os exemplos acima não nos permitem reconhecer na vogal - 0 - 
um elemento infixal, pois esta se encontra no interior do vocábulo composto. O verdadeiro caráter da vogal terminal do primeiro elemento do composto é muito mais sufixal (diferentemente do que afirma Li Ching), sobretudo levando-se em conta a produtividade desse tipo de formação e a frequiente redução do composto ao seu primeiro elemento.

Herculano de Carvalho (1963, s.v.afixo (p.521)) chega mesmo a identificar no pronome átono em mesóclise um infixo. $O$ exemplo apresentado - fá-lo-ei-é altamente questionável: a variante lo não é morfema verbal e a existência de fá-lo (em comparação com fá-lo-ei) constitui um argumento a mais para negar o valor infixal do pronome ${ }^{2}$.

Na Gramática construtural da língua portuguesa, Back e Mattos (1972, p.373) assinalam o caráter infixal de -inho em nomes próprios masculinos terminados em -s- ou -a: Carlos - Carl-inh-os, Lucas - Luquinh-as, Marcos - Marqu-inh-os, Mota - Mot-inh-a. Um exame mais atento dos exemplos arrolados permite-nos rever a questão; trata-se, na verdade, do sufixo -inho num comportamento específico. A tendência a dizer Carlinho e, com maior frequiência, Luquinha e Marquinho (além do par Rubens - Rubinho, em que na última forma não ocorre -s) revela com clareza que o sufixo diminutivo tende a recuperar a sua posição normal; confirmam-no também alguns nomes próprios femininos: Lurdes Lurd-inha, Mercedes - Merced-inha, em que se verifica a perda do $-s^{3}$.

Heckler, Back e Massing (1984, p. XVIII), a respeito do infixo em português, observam:

"Há gramáticos que negam a existência de infixos na Língua Portuguesa, embora possamos apresentar casos, como: $f a z$, $f e z$, fiz, em que a alternância vocálica nos parece um verdadeiro infixo. Para haver um verdadeiro infixo, este deve ser um morfema, isto é, uma unidade significativa e não apenas uma unidade funcional. (...)".

É interessante observar que o pronome átono mesoclítico também foi dado como exemplo de infixo por gramáticos mais antigos. Cf. João Ribeiro (1930, p.118).

3 Herculano de Carvalho (1973, p.530 (n.34)) assinala também a ocorrência de infixo em lapinhos. Contudo, a frequiência maior de lapinho confirma a conclusão acima. 
A afirmação está, sem dúvida, atenuada, mas cabe observar que a existência de infixos é, aqui, também questionável. Lembre-se que $M$. Câmara (1964, §50 (p.104)), ao estabelecer a diferença entre morfemas alternativos e infixos, esclarece que estes últimos são morfemas aditivos que se integram num radical existente na língua. Com efeito, retomando o exemplo latino acima mencionado - uiNco/uici -, constata-se a ocorrência de uic-; já nos exemplos apresentados por Heckler et alii, com a eliminação da vogal se obtém $f . . . z$, que não ocorre como lexema em português. Neste caso, deve-se falar em alternância vocálica (exceto em $f a z$ ); a raiz $f . . . z$ é teórica e só se realiza como lexema com a inserção da vogais $-e-\mathrm{e}-i-$.

Do ponto de vista diacrônico, temos, aqui, um exemplo de metafonia: feci $>$ fiz, fecit $>$ fez. A metafonia constitui o ponto de partida para explicar os numerosos casos de alternância vocálica em nossa língua.

Embora os argumentos acima nos levem a negar a existência de infixos em português, constituem, inegavelmente, veios de pesquisa importantes e exploráveis, como passamos a indicar.

Os fonemas de ligação remetem-nos ao problema dos morfes vazios, que também são representados pelas vogais temáticas verbais e nominais ${ }^{4}$.

No caso de formas como Carlinhos, assinalou-se que estávamos diante de um comportamento particular do sufixo diminutivo. Note-se que a variante -zinho também apresenta comportamento específico; relativamente ao radical, é menos coesa que os demais sufixos, como se pode verificar pelo plural leõezinhos, em que a flexão de número não se dá apenas no final do vocábulo. Com o sufixo -mente temos também a flexão da base: generosamente. Pode-se, portanto, afirmar que o levantamento de sufixos implica também a referência às suas particularidades de emprego.

Saliente-se que as vogais temáticas verbais nem sempre são morfes vazios. No par amAs - amEs é a oposição -A-/-E- que permite distinguir o presente do indicativo do pres. do subjuntivo; aqui, a vogal temática é morfema significativo. 
Finalmente, nos exemplos de alternância vocálica, cumpre assinalar que esta é um traço marcante nas flexões nominal e verbal do português. Causa, portanto, estranheza o fato de não termos ainda um estudo exaustivo do fenômeno da alternância em nossa língua ${ }^{5}$.

Encerrando nossas considerações, queremos esclarecer que não negamos, taxativamente, a existência de infixos em português; os argumentos propostos pelo diferentes autores aqui estudados não nos pareceram convincentes, o que não significa que não estejamos abertos à consideração de novas propostas sobre o tema em questão.

\section{BIBLIOGRAFIA}

BACK, E.; MATTOS, G. (1972) Gramática construtural da língua portuguesa. São Paulo, FT.D. (I vol.).

CÂMARA, Jr., J. M. (1956) Dicionário de fatos gramaticais. Rio de Janeiro, MEC/Casa de Rui Barbosa.

(1964) Princípios de lingüística geral. 4. ed. Rio de Janeiro, Acadêmica.

CARVALHO, J. G. H. de (1963) Afixo. In Enciclopédia Luso-Brasileira de Cultura. Lisboa, Verbo (vol.1).

(1973) Teoria da linguagem. Coimbra, Atlântida (tomo II).

CAVACAS, A. D. (1992) A língua portuguesa e sua metafonia. Rio de Janeiro, Lucerna.

CHING, Li (1973) Sobre a formação de palavras com prefixos em português actual. Boletim de Filologia, XXII, p.213-25, Lisboa.

HECKLER, E.; BACK, S.; MASSING, E. (1984) Dicionário morfológico da língua portuguesa. São Leopoldo, Unisinos (vol. I).

HOCKETT, C. F. (1947) Problems of morphemic analysis. Language, XXIII, p. 321-43, New York.

LIMA, M. P. de S. (1945) Gramática portuguesa. 2. ed. Rio de Janeiro, J. Olympio.

MEILLET, A.; VENDRYES, J. (1960) Traité de grammaire comparée des langues classiques. 3. ed. Paris, H. Champion.

RIBEIRO, J. (1906) Diccionario grammatical. 3. ed. Rio de Janeiro, Francisco Alves. . (1930) Grammatica portugueza. 21. ed. Rio de Janeiro, Francisco Alves.

5 O que se conhece de mais completo sobre o assunto é a importante dissertação de Cavacas, mas trata-se de trabalho publicado em 1917 (reedição em 1992), a reclamar atualização em alguns pontos. 
KEHDI, Valter. 0 problema do infixo em português.

ABSTRACT: This article is a survey of the various views about the existence of infixes in Portuguese, followed by critical comments. It aims to show that, most probably, this type of morpheme is non-existent in the language under study.

Keywords: infix, vowel gradation, connecting vowels/consonants. 